\title{
Antibiotic prescribing practices of dentists at Medunsa Oral Health Centre
}

\section{ABSTRACT}

\section{Introduction}

Inappropriate prescribing and excessive use of broad spectrum antibiotics are reported to be leading contributors to the development of antimicrobial resistance worldwide.

\section{Aims and objectives}

To examine the antibiotic prescribing practices of dentists in Medunsa Oral Health Centre.

The range of conditions for which antibiotics were prescribed was identified and the characteristics of antibiotic prescribing were described. The prescription practices were investigated for concurrence with available evidence.

\section{Design}

A retrospective, cross-sectional descriptive study in which existing medical records were reviewed.

\section{Methods}

Medical records of patients who received medication from the dispensary during March 2017 were reviewed.

Data in the health history questionnaire and data related to demographic characteristics, condition(s) diagnosed, procedure carried out and medication prescribed were extracted.

Information from recent independent reviews and individual studies was reviewed to assess the alignment of prescribing practice with available evidence. References in retrieved review articles were used to identify additional studies.

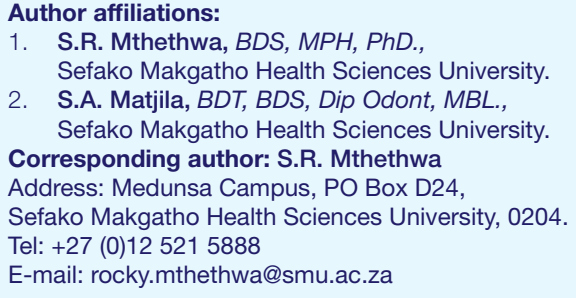

Results

Healthy patients comprised $74.6 \%$ of the study participants. Perioperative prophylactic antibiotics for dental extractions accounted for $59.1 \%$ of the prescriptions. Amoxicillin 500mg, three times a day, was prescribed most frequently (74.5\%).

\section{Conclusions}

Inappropriate prescribing for healthy patients is a common feature of the antibiotic prescribing practice at $\mathrm{MOHC}$.

\section{INTRODUCTION AND BACKGROUND}

Inappropriate prescribing and excessive use of broad spectrum antibiotics are reported to be leading contributors to the development of antimicrobial resistance worldwide. ${ }^{1}$

Antibiotics are occasionally prescribed by dentists in dental practice. The rate of antibiotic prescribing by dentists has been reported to range between $7 \%$ and $11 \%$ worldwide 2,3 - the rate in South Africa is unknown.

The indications for the use of systemic antibiotics in dentistry are limited since the most common dental infections present in the form of pulpitis and periapical periodontitis and require only operative measures such as fillings, root canal therapy, or extraction if the tooth is not restorable..$^{4,5}$

Antibiotics are typically prescribed for some of the following purposes: as treatment for acute odontogenic infections; as treatment for nonodontogenic infections; as prophylaxis against focal infection in patients at risk (endocarditis and joint prostheses); and as prophylaxis against local infection and systemic spread in oral surgery. ${ }^{6,7}$

Reviews of literature on the subject found that antibiotic use in dental practice is characterised by empirical prescription involving the use of a narrow range of broad spectrum antibiotics for short periods of time - typically no more than $7-10$ days. ${ }^{4-6}$ 
Antibiotic prescription has been found to be almost invariably associated with the prescription of analgesics, particularly non-steroidal anti-inflammatory drugs (NSAIDs). ${ }^{6}$

Instances of inappropriate and excessive use of antibiotics in dental practice occur where antibiotics are prescribed for: non-indicated conditions such as dry socket, acute periapical infection and pulpitis; ${ }^{5,8}$ non-clinical factors such as patient's expectation of an antibiotic prescription, convenience, and demand necessitated by the social background of the patients; ${ }^{4}$ and where antibiotics are prescribed to cover either a defect in aseptic clinical technique or improperly sterilized equipment. ${ }^{9}$ It has also been reported that some dentists prescribe antibiotics for viral infections like herpes simplex virus- 1 infections. ${ }^{10}$

Very little is known about the antibiotic prescribing practices of dentists in South Africa. A 2012 survey, which had an extremely low response rate, investigated their knowledge of treatment guidelines and prescribing practices for antibiotic prophylaxis.

The study found that most dentists were aware of treatment guidelines. However, few actually followed the recommendations for antibiotic prophylaxis, and few correctly prescribed for patients allergic to penicillin. ${ }^{11} \mathrm{~A}$ more recent study has described the antibiotic prescribing patterns of dentists following tooth extraction. The results of this study found that the antibiotic prescribing patterns do not appear to follow a coherent set of guidelines or meaningful indications for antibiotic use. ${ }^{12}$

This study seeks to examine the antibiotic prescribing practices of dentists in Medunsa Oral Health Centre, a dental school and referral hospital in Garankuwa on the outskirts of Pretoria.

\section{OBJECTIVES OF THE STUDY}

- To describe the demographic and clinical characteristics of patients who received medication from the dispensary at Medunsa Oral Health Centre during March 2017.

- To describe the characteristics of antibiotic prescribing.

- To identify the range of conditions/procedures for which antibiotics were prescribed and to investigate whether prescription practices were in line with available evidence.

\section{MATERIALS AND METHODS}

\section{Study design}

This was a retrospective, cross-sectional descriptive study in which existing medical records were reviewed.

\section{Target population}

The sampling frame consisted of medical records of 452 patients who received medication from the dispensary at Medunsa Oral Health Centre during March 2017.

\section{Study sample}

The ideal sample size was estimated at 159 patient records in Epi Info Version 3.5.4 software at the confidence interval of $95 \%$ and absolute precision of $5 \%$ assuming an antibiotic prescription rate of $80 \%$ among patients who receive medications from the dispensary. However, a sample of only 155 was drawn.

\section{Sampling method}

A systematic random sample was selected i.e. a list of the entire population using patient names was prepared in Excel; the sample size of 159 was divided into the total population (452) to calculate the Kth number. The Kth number was 3. A random starting point was selected (a number between 1 and 3 ), we selected 3. We started with the third person and picked every third person on the list. ${ }^{13}$

\section{MEASUREMENTS}

\section{Data collection}

Medical records of patients who received medication from the dispensary during March 2017 were reviewed. Data in the health history questionnaire and data related to demographic characteristics, condition(s) diagnosed, procedure carried out and medication prescribed were extracted.

Information from recent independent reviews and individual studies was reviewed to assess the alignment of prescribing practice with available evidence. References in retrieved review articles were used to identify additional studies.

\section{Definition of variables and terms}

Age and Gender refer to patient age and sex as recorded in medical records.

\section{Ethical considerations}

Ethical approval for the study was granted by the Ethics Committee of the Sefako Makgatho Health Sciences University. Permission to conduct the study was granted by the Chief Executive Officer (CEO) of Medunsa Oral Health Centre.

\section{STATISTICAL ANALYSIS}

Data was captured, coded and cleaned in Microsoft excel software and then transferred to Statistical Analysis Software (SAS) software for analysis. Means, frequencies and proportions (percentages) were calculated.

\section{RESULTS}

Data of a systematic random sample of 142 records was analysed. A response rate of $89.3 \%$ was achieved.

The age group 18-34 years comprised a little less than sixty percent $(58.5 \%)$ of the study participants. Females constituted $52.1 \%$. 


\begin{tabular}{|c|c|c|c|c|c|c|}
\hline \multicolumn{7}{|c|}{ Gender } \\
\hline \multirow{2}{*}{$\begin{array}{l}\text { Age groups } \\
1-17 \text { years }\end{array}$} & \multicolumn{2}{|c|}{ Female $\mathrm{n}(\%)$} & \multicolumn{2}{|c|}{ Male n (\%) } & \multicolumn{2}{|r|}{ Totals } \\
\hline & 7 & (4.9) & 5 & (3.5) & 12 & (8.5) \\
\hline $18-34$ years & 43 & (30.3) & 39 & (27.5) & 83 & (58.5) \\
\hline $35-51$ years & 13 & (9.2) & 17 & (12.0) & 30 & (21.1) \\
\hline $52-68$ years & 8 & (5.6) & 5 & (3.5) & 13 & (9.2) \\
\hline $69+$ years & 3 & (2.1) & 1 & $(0.7)$ & 4 & (2.8) \\
\hline Total & 74 & (52.1) & 67 & (47.2) & 142 & (100) \\
\hline
\end{tabular}

\begin{tabular}{|c|c|c|c|c|}
\hline \multirow{2}{*}{$\begin{array}{l}\text { History of systemic } \\
\text { illness }\end{array}$} & \multicolumn{2}{|c|}{ Antibiotic prescribed } & \multicolumn{2}{|c|}{ Totals } \\
\hline & Yes n (\%) & No n (\%) & & \\
\hline None & $64(44.8)$ & $36(25.4)$ & $106^{*}($ & (74.6) \\
\hline Diabetes & 2 (1.4) & $1 \quad(0.7)$ & 3 & $(2.1)$ \\
\hline Hypertension & $6 \quad(4.2)$ & $2(1.4)$ & 8 & $(5.6)$ \\
\hline Heart condition & 2 (1.4) & $0 \quad(0)$ & 2 & (1.4) \\
\hline HIV & $9 \quad(6.3)$ & (0) & 9 & (6.3) \\
\hline Allergy & $3 \quad(2.1)$ & $1(0.7)$ & 4 & $(2.8)$ \\
\hline Flu & $1 \quad(0.7)$ & $0 \quad(0)$ & 1 & $(0.7)$ \\
\hline $\begin{array}{l}\text { Localized illness - } \\
\text { Ear condition/Back } \\
\text { problem/operation/ } \\
\text { Breast operation/ } \\
\text { Epilepsy/ Asthma/ } \\
\text { mental illness/ } \\
\text { psychosomatic } \\
\text { disturbance }\end{array}$ & $6 \quad(4.2)$ & $3(2.1)$ & 9 & (6.3) \\
\hline Total & $93(65.5)$ & $43(30.3)$ & $142^{*}$ & (100) \\
\hline
\end{tabular}

Antibiotics were prescribed for $65.5 \%$ of the study participants. Patients with no history of systemic illness comprised a little less than three-quarters (74.6\%) of the study participants - three out of five (64/106) were prescribed antibiotics.

HIV infected patients constituted the second largest category (6.3\%) of study participants - all of them were prescribed antibiotics.

\begin{tabular}{l|cr|}
\hline \multicolumn{3}{|l|}{ Table 3: Number of antibiotics per prescription } \\
\hline Antibiotics $(\mathrm{n})$ & \multicolumn{3}{l|}{ Prescriptions $\mathrm{n}(\%)$} \\
\hline 1 & 77 & $(82.8)$ \\
2 & 16 & $(17.2)$ \\
Total & 93 & $(100)$ \\
\hline
\end{tabular}

Less than two percent (1.4\%) of study participants had a history of heart condition(s) - both patients were prescribed antibiotics for bacterial endocarditis prophylaxis.

\begin{tabular}{|l|rr|}
\hline Table 5: Duration of antibiotic prescription & \multicolumn{2}{c|}{ Patient $\mathrm{n}(\%)$} \\
\hline Days & 2 & $(2.2)$ \\
\hline day & 2 & $(89.2)$ \\
5 days & 83 & $(8.6)$ \\
7 days & 8 & $(100)$ \\
\hline Total & 93 & \\
\hline
\end{tabular}

Four out of five patients were prescribed a single antibiotic. Amoxicillin 500mg, three times a day, was prescribed most frequently (74.5\% i.e. $82 / 110)$. A lone patient was prescribed Augmentin 625mg.

A five-day supply of antibiotics was prescribed for nine out of ten patients.

\begin{tabular}{|c|c|c|c|c|c|c|}
\hline \multirow{3}{*}{$\begin{array}{l}\text { Conditions/ } \\
\text { Procedures } \\
\text { Infective endocarditis }\end{array}$} & \multicolumn{4}{|c|}{ Antibiotics } & \multicolumn{2}{|c|}{ Totals } \\
\hline & \multicolumn{2}{|c|}{ Yes n (\%) } & \multicolumn{2}{|c|}{ No n (\%) } & \multirow[b]{2}{*}{2} & \multirow[b]{2}{*}{ (100) } \\
\hline & 2 & (100) & 0 & (0) & & \\
\hline Dry socket & 3 & (100) & 0 & (0) & 3 & (100) \\
\hline $\begin{array}{l}\text { Emergency/Elective } \\
\text { root canal therapy }\end{array}$ & 4 & (80) & 1 & (20) & 5 & (100) \\
\hline Periodontal diseases & 6 & (66.7) & 3 & (33.3) & 9 & (100) \\
\hline $\begin{array}{l}\text { Routine/surgical ex } \\
\text { tractions }\end{array}$ & 55 & (78.6) & 15 & (21.4) & 70 & (100) \\
\hline Pericoronitis & 3 & (75) & 1 & (25) & 4 & (100) \\
\hline Biopsy & 2 & (50) & 2 & (50) & 4 & (100) \\
\hline No diagnosis & 5 & (55.6) & 4 & (44.4) & 9 & (100) \\
\hline Painful tooth & 3 & (75) & 1 & (25) & 4 & (100) \\
\hline Other conditions & $10^{*}$ & (31.2) & 22 & (68.8) & 32 & (100) \\
\hline Total & 93 & (65.5) & 49 & (34.5) & 142 & (100) \\
\hline
\end{tabular}

Antibiotics were prescribed for a little less than two-thirds (65.5\%) of the study participants. Perioperative prophylactic antibiotics for dental extractions accounted for $59.1 \%$ (55/93) of the prescriptions.

Healthy patients comprised a little less than two-thirds $(65.5 \%)$ of the recipients of perioperative prophylaxis. HIV infected patients comprised the second highest category (10.9\%) of perioperative prophylaxis recipients.

Routine extractions accounted for $54.5 \%$ of perioperative prophylactic antibiotics prescriptions.

\begin{tabular}{|c|c|c|c|c|c|c|c|c|c|}
\hline \multirow[t]{3}{*}{ Types of antibiotics } & \multicolumn{8}{|c|}{ Dosage } & \multirow[t]{3}{*}{ Totals } \\
\hline & $125 \mathrm{mg}$ & $200 \mathrm{mg}$ & $250 \mathrm{mg}$ & $400 \mathrm{mg}$ & $500 \mathrm{mg}$ & $625 \mathrm{mg}$ & 1 gram & 2gram & \\
\hline & t.d.s. & t.d.s. & t.d.s. & t.d.s. & t.d.s. & & stat & stat & \\
\hline Amoxicillin & 3 & N/A & 5 & N/A & 82 & N/A & 1 & 1 & 92 \\
\hline Metronidazole & N/A & 3 & N/A & 14 & N/A & N/A & N/A & $N / A$ & 17 \\
\hline Augmentin & N/A & N/A & N/A & N/A & N/A & 1 & N/A & N/A & 1 \\
\hline Totals & 3 & 3 & 5 & 14 & 82 & 1 & 1 & 1 & 110 \\
\hline N/A: not available & & & & & & & & & \\
\hline
\end{tabular}




\begin{tabular}{|c|c|c|c|c|c|c|}
\hline \multirow{3}{*}{$\begin{array}{l}\text { History of systemic } \\
\text { illness } \\
\text { None }\end{array}$} & \multicolumn{4}{|c|}{ Antibiotics } & \multirow{2}{*}{\multicolumn{2}{|c|}{ Totals }} \\
\hline & \multicolumn{2}{|c|}{$\begin{array}{c}\text { Routine } \\
\text { extractions } \\
\text { n (\%) }\end{array}$} & \multicolumn{2}{|c|}{$\begin{array}{c}\text { Surgical } \\
\text { extractions } \\
n(\%)\end{array}$} & & \\
\hline & 18 & (50) & 18 & (50) & 36 & (100) \\
\hline Diabetes & 1 & (100) & 0 & (0) & 1 & (100) \\
\hline Hypertension & 0 & (0) & 1 & (100) & 1 & (100) \\
\hline Heart condition & 2 & (100) & 0 & (0) & 2 & (100) \\
\hline HIV & 5 & (83.3) & 1 & (16.7) & 6 & (100) \\
\hline Allergy & 0 & (0) & 1 & (100) & 1 & (100) \\
\hline $\begin{array}{l}\text { Localized illness } \\
\text { - Back operation/ } \\
\text { Psychosomatic } \\
\text { disturbance/ } \\
\text { Tonsillitis }\end{array}$ & 3 & (100) & 0 & (0) & 3 & (100) \\
\hline $\begin{array}{l}\text { Missing history of } \\
\text { illness data }\end{array}$ & 1 & (20) & 4 & (80) & 5 & (100) \\
\hline Total & 30 & (54.5) & 25 & (45.5) & 55 & (100) \\
\hline
\end{tabular}

\section{DISCUSSION}

This study set out to describe the antibiotic prescribing practices of dentists at Medunsa Oral Health Centre. The alignment of the prescribing practices to current evidence was also described.

\section{Demographic characteristics}

The results of this study show that the age group 18-34 years comprised a little less than sixty percent of the study participants. This finding does not support the previous research of Marra and colleagues (2016) who found that the rate of antibiotic prescribing increased the most for dental patients 60 years or older in British Columbia, Canada. ${ }^{8}$

The population pyramid of South Africa, which is typical of a developing country, might explain this contradiction.

Females constituted $52.1 \%$ of the study participants, which seem to be consistent with those of other studies which found that more women than men were prescribed antibiotics at dental clinics. ${ }^{14}$

\section{Clinical characteristics}

The current study found that patients with no history of systemic illness comprised a little less than threequarters $(74.7 \%)$ of study participants. This result seem to be consistent with other research which found that the majority of dental patients are healthy. ${ }^{12,15}$

HIV infected patients constituted the second largest category (6.3\%) of study participants. The findings of the current study are consistent with those of Ogbebor and colleagues (2015) who found that the prevalence of HIV among dental patients in Nigeria was below the national average ${ }^{16}$ - South Africa's national average is $12.6 \% .^{17}$
The HIV prevalence data obtained in the current study cannot be extrapolated to all patients who visited $\mathrm{MOHC}$ during March and therefore need to be interpreted with caution.

Less than two percent (1.4\%) of the study subjects had a history of heart condition(s). This finding was unexpected considering that the incidence of symptomatic rheumatic heart disease in adults and the prevalence of asymptomatic rheumatic heart disease in schoolchildren are high. Rheumatic heart disease is the major predisposing factor of infective endocarditis in young adults. ${ }^{18}$ It is difficult to explain this result.

\section{Characteristics of antibiotic prescribing}

The results of this study indicate that antibiotics were prescribed for $65.5 \%$ of the study participants. This result has not previously been described.

Unfortunately, the prevalence of antibiotic prescribing at $\mathrm{MOHC}$ during March could not be established due to inaccurate patient data.

There was no clear separation of data of patients on the hospital appointment system from that of patients not on the hospital appointment system, who were referred for general dental care and/or for initial assessment in the relevant specialty clinics. This is an important issue for future research.

The current study found that four out of five patients were prescribed a single antibiotic; amoxicillin 500mg, three times a day, was prescribed most frequently $(82 / 94)$, and that a five-day supply of antibiotics was prescribed for nine out of ten patients. This study produced results which corroborate the findings of a great deal of the previous work in this field. ${ }^{4-6,12}$

The most interesting finding was that three out of five (64/106) patients with no history of systemic illness were prescribed antibiotics.

Considering that the indications for the use of systemic antibiotics in dentistry are limited, the high frequency of antibiotic prescribing observed in the current study is inappropriate.

Another important finding was that a little more than half $(36 / 64)$ of patients with no history of systemic illness were prescribed antibiotics for extractions - an equal number (18) for routine and surgical extractions respectively.

Although, these results differ from those of Lalloo and colleagues (2016), they are consistent with those of Akinbami and Osagbemiro (2015) who found that 55\% of healthy patients who underwent routine extractions were prescribed antibiotics. ${ }^{12,15}$

The present finding seems to be consistent with other research which found that dentists were more likely to prescribe antibiotics for individuals undergoing extraction of impacted teeth. ${ }^{12}$ 
The results of this study show that all HIV infected patients who received medication from the dispensary were prescribed antibiotics - two-thirds (6/9) of the prescriptions were for extractions. This finding was unexpected. Further research should be done to investigate the indications for antibiotic prescribing in HIV infected dental patients.

\section{Range of conditions/procedures for which antibiotics were prescribed}

The prevalence of antibiotic prescribing for conditions other than extractions has not previously been described.

\section{Infective endocarditis prophylaxis}

The results of this study show that antibiotics dispensed to prevent infective endocarditis constituted $2.2 \%$ of the antibiotic prescriptions filled. Antibiotic prophylaxis to prevent infective endocarditis is widely accepted by the dental profession. ${ }^{19}$ The effectiveness of such antibiotic prophylaxis in humans, however, remains unproven. ${ }^{20}$

The more recent Cochrane review in 2013 concluded that there remains no evidence about whether antibiotic prophylaxis is effective or ineffective against bacterial endocarditis in people at risk who are about to undergo an invasive dental procedure. ${ }^{21}$ However, the prophylaxis guidelines recommended by AHA, ESC and BSAC are applied in South Africa. ${ }^{22}$ The current study found that the regime recommended for patients not hypersensitive to penicillin was ordered. ${ }^{19}$

\section{Dry socket}

The current study found that antibiotics dispensed for the treatment of dry socket constituted 3.2\% of the antibiotic prescriptions filled. The range of treatments for a dry socket includes non-dressing and dressing interventions directed locally to the socket and, where appropriate, the prescription of systemic antibiotics. ${ }^{23,24}$

The level of evidence for effectiveness of most management guidelines was found to be low. ${ }^{24,25}$ They were found to be based on expert opinions and clinical experience. ${ }^{24}$ A recent Cochrane review in 2012 concluded that there was insufficient evidence to determine the effects of any of the local interventions to treat dry socket. ${ }^{26}$

It is however widely accepted that systemic antibiotics should not be prescribed for the treatment of dry socket as they have no additional advantage over local treatments directed to the socket in a nonimmune-compromised patient, due to the potential for development of resistant strains to the antibiotics and other side effects such as hypersensitivity. ${ }^{24}$ The results of this study indicate that two thirds of the cases of dry socket prescribed antibiotics had concomitant illnesses or immunodeficiency - flu and diabetes. Both conditions are indicated for antibiotic therapy according to current evidence.
Another important finding was that antibiotics were prescribed for a healthy case of dry socket, which is contrary to current evidence.

\section{Endodontics}

The results of this study indicate that antibiotics dispensed for elective or emergency root canal therapy constituted $4.3 \%$ of antibiotics prescribed. In endodontics, antibiotics are unnecessary in irreversible pulpitis, necrotic pulps and localised acute apical abscesses. ${ }^{27,28}$

The lack of blood circulation in the root canal in these conditions prevents antibiotics reaching the area. ${ }^{29}$ Antibiotics are however indicated as an adjunct during endodontic therapy in acute apical abscess in medically compromised patients, acute apical abscess with systemic involvement, progressive infections and persistent infections, as they assist in the prevention of the spread of infection. ${ }^{29}$

The diagnoses of different pulp diseases were not recorded in this study. This made it difficult to determine the extent that practice deviates from current evidence.

\section{Periodontics}

The results of this study indicate that antibiotics dispensed to treat periodontal diseases constituted $6.5 \%$ of prescribed antibiotics. Chronic inflammatory periodontal conditions are not indicated for antibiotics; systemic antimicrobials should only be used in acute periodontal conditions where drainage or debridement is impossible, where there is local spread of the infection or where systemic upset has occurred. ${ }^{30}$

Clinical trials have produced evidence of additional benefits when metronidazole alone or with amoxicillin in various doses and durations are used as adjuncts to scaling and root planing for the treatment of chronic periodontal disease. ${ }^{31-34}$ Clear guidelines for the use of these agents in the clinical practice are not yet available. ${ }^{35}$

The low rate of antibiotic prescribing in the current study supports previous research in the field of systemic antibiotics in the treatment of periodontitis. ${ }^{35}$

\section{Extractions}

Perioperative prophylaxis for dental extractions accounted for $59.1 \%(55 / 93)$ of the antibiotics prescriptions.

\section{Routine dental extractions}

The results of recent clinical trials show that there is no significant difference in the incidence of post extraction complications in healthy patients undergoing routine dental extractions prescribed perioperative prophylactic antibiotics and those not prescribed antibiotics. ${ }^{15,36}$ However, patients at higher risk of infection are more likely to benefit from 
prophylactic antibiotics. ${ }^{37}$ Akinbami and Osagbemiro (2015) found that the type of extraction, difficulty of extraction and adherence to postoperative instructions were important associated factors that determined the occurrence of postoperative complications. ${ }^{15}$

\section{Surgical extraction of lower third molars}

The issue of prophylactic antibiotic therapy in third molar surgery in healthy patients is highly controversial. Conflicting results have been reported. However a meta-analysis of 16 clinical trials with a total of 2,932 participants published in 2007 concluded that systemic antibiotics given before the surgery were effective in reducing the frequencies of dry socket and wound infection after third molar surgery. ${ }^{38}$

A more recent Cochrane review in 2013 of 18 doubleblind placebo-controlled trials with a total of 2456 participants concluded that there is evidence that prophylactic antibiotics reduce the risk of infection, dry socket and pain following third molar extraction and result in an increase in mild and transient adverse effects.

The review further concluded that patients at higher risk of infection, the risk may be up to $25 \%$ in patients who are already sick or have low immunity, are more likely to benefit from prophylactic antibiotics, because infections in this group are likely to be more frequent, associated with complications and be more difficult to treat. ${ }^{37}$ A more recent prospective cohort study corroborates these reviews. ${ }^{39}$

\section{Pericoronitis}

The results of this study indicate that $3.2 \%$ of antibiotics were dispensed to treat pericoronitis. Adjunctive antimicrobial therapy is recommended to treat acute pericoronitis if there are systemic signs and symptoms. ${ }^{40}$. The results of the current study are in agreement with accepted practice.

\section{Intra-oral soft tissue biopsy}

Antibiotic prophylaxis to prevent infective endocarditis should be given in advance of biopsies. ${ }^{19}$

Patients at increased risk for postoperative wound infection should be placed on oral antibiotic therapy following the surgical procedure. ${ }^{41}$ The results of the current study are in agreement with accepted practice.

\section{No diagnosis}

The results of this study indicate that $5.4 \%$ of antibiotics were dispensed in the absence of a diagnosis. This unanticipated finding has not previously been described.

\section{Painful tooth}

The current study found that antibiotics dispensed for the treatment of the non-specific symptom of painful tooth constituted $3.2 \%$ of the antibiotic prescriptions filled. This finding was unexpected and unfortunate. Conditions such as acute periapical infection and pulpitis are not indicated for antibiotic treatment. $5,8,27,28$

\section{Limitations of the study}

The prevalence of antibiotic prescribing at $\mathrm{MOHC}$ during March could not be determined due to inaccurate data.

The potential threats to the internal validity of the study were those arising from non-response bias - a response rate of $89.3 \%$ was achieved, and incomplete records.

\section{CONCLUSION}

Inappropriate prescribing for healthy patients is a common feature of the antibiotic prescribing practice at $\mathrm{MOHC}$.

\section{References}

1. WHO. Antimicrobial resistance: global report on surveillance 2014. World Health Organization, Geneva.

2. Cleveland JI, Kohn WC. Antimicrobial resistance and dental care: a CDC perspective. Dent Abstr. 1998;108-10.

3. Johnson TM, Hawkes J. Awareness of antibiotic prescribing and resistance in primary dental care. Prim Dent J.2014; 3(4):44-7.

4. Dar-Odeh NS, Abu-Hammad OA, Al-Omiri MK, Khraisat AS, Shehabi AA. Antibiotic prescribing practices by dentists: a review. Therapeutics and Clinical Risk Management 2010; 6:301-6.

5. Bennadi D. Antimicrobial stewardship - an alarming call in dentistry. International Journal of Pharmacy and Pharmaceutical Sciences 2014; 6(2): 46-9.

6. Poved-Roda, Bagán JV, Sanchis-Bielsa JM, Carbonell-Pastor E. Antibiotic use in dental practice: A review. Med Oral Patol Oral Cir Buccal. 2007; 12(3):E186-92.

7. Ramu C, Padmanabhan TV. Indications of antibiotic prophylaxis in dental practice- Review. Asian Pac J Trop Biomed. 2012; 2(9): 749-54.

8. Marra F, George D, Chong M, Sutherland S, Patrick DM. Antibiotic prescribing by dentists has increased: Why? J Am Dent Assoc. 2016; 147(5):320-7

9. Al-Haroni M, Skaug N. Knowledge of prescribing antimicrobials among Yemeni general dentists. Acta Odontol Scand. 2006;64(5):274-80.

10. Demirbas F, Gjermo PE, and Preus HR. Antibiotic prescribing practices among Norwegian dentists. Acta Odont Scand. 2006; 64(6): 355-9.

11. Owen CP1, Huang WH. Antibiotic prophylaxis for dental procedures: is it necessary? SADJ. 2012; 67(7):413-9.

12. Lalloo R, Solanki G, Ramphoma K, Myburgh N. Antibioticprescribing patterns of South African dental practitioners following tooth extractions. J Invest Clin Dent. 2017;8:e12247

13. Indiana University Bloomington. Sampling \& How to Use a Random Number Table. Available: http://www.indiana. edu/ educy520/sec6342/week_04/random_num_table.pdf Accessed [05 April 2017].

14. Peric M, Perkovic I, Romic M, et al. The pattern of antibiotic prescribing by dental practitioners in Zagreb, Croatia. Cent Eur J Public Health. 2015; 23 (2): 107-13.

15. Akinbami B.O, Osagbemiro B.B. Is routine antibiotic prescription following exodontias necessary? A randomized controlled clinical study. J Dent Oral Hyg. 2015; 7 (1): 1-8. 
16. Ogbebor O.G, Obisesan B, Madukwe I. U, Azodo C.C. Prevalence of undiagnosed HIV infection among dental patients in a Nigerian secondary healthcare facility. J Int Soc Prev Community Dent. 2015; 5(3): 237-41.

17. Statistics South Africa. Statistical Release P0302: Mid-year population 2017. Available:

18. https://www.statssa.gov.za/publications/P0302/P03022015. pdf [Accessed 27 August 2013].

19. Zühlke LJ, Engel ME, Watkins D, Mayosi BM. Incidence, prevalence and outcome of rheumatic heart disease in South Africa: a systematic review of contemporary studies. Int $\mathrm{J}$ Cardiol. $2015 ; 199: 375-83$.

20. Jankelow D, Cupido B, Zuhlke L, et al. Prevention of infective endocarditis associated with dental interventions: South African Heart Association position statement, endorsed by the South African Dental Association. SADJ 2017; 72(7): 170-4.

21. Chambers JB, Shanson D, Hall R, Pepper J, Venn G, McGurk M. Antibiotic prophylaxis of endocarditis: the rest of the world and NICE. J R Soc Med. 2011; 104(4): 138-40.

22. Glenny AM1, Oliver R, Roberts GJ, Hooper L, Worthington HV. Antibiotics for the prophylaxis of bacterial endocarditis in dentistry. Cochrane Database Syst Rev 2013;10:CD003813.

23. van der Bijl jr P, van der Bijl P. Infective endocarditis and antibiotic prophylaxis--an update for South African dental practitioners. SADJ 2014; 69(3): 118-21.

24. Tarakji B, Saleh LA, Umair A, Azzeghaiby SN, Hanouneh S. Systemic review of dry socket: aetiology, treatment, and prevention. J Clin Diagn Res. 2015; 9(4):ZE10-3.

25. Bowe Dc, Rogers S, Stassen LFA. The management of dry socket/alveolar osteitis. Journal of the Irish Dental Association 2011; 57(6): 305-10

26. Sharif MO, Dawoud BeS, tsichlaki A, Yates JM. Intervention for the prevention of dry socket: an evidence-based update. British Dental Journal 2014; 217(1): 27-30.

27. Daly B, Sharif MO, Newton T, Jones K, Worthington HV. Local interventions for the management of alveolar osteitis (dry socket) (Review). Cochrane Database of Systematic Reviews 2012; 12: CD006968.

28. Agnihotry A, Fedorowicz Z, van Zuuren EJ, Farman AG, Al-Langawi JH . Antibiotic use for irreversible pulpitis. Cochrane Database Systematic Reviews 2016; 2: CD004969.

29. Cope A, Francis N, Wood F, Mann MK, Chestnutt IG. Systemic antibiotics for symptomatic apical periodontitis and acute apical abscess in adults. Cochrane Database Systematic Reviews 2014; 6: CD010136.
30. Segura-Egea JJ, Gould K, \en BH, et al. Antibiotics in Endodontics: a review. Int Endod J. 2017; 50(12):1169-84.

31. Addy M, Martin MV. Systemic antimicrobials in the treatment of chronic periodontal diseases: a dilemma. Oral Dis. 2003; 9 Suppl 1:38-44.

32. Feres M, Soares GM, Mendes JA, et al. Metronidazole alone or with amoxicillin as adjuncts to non-surgical treatment of chronic periodontitis: a 1-year double-blinded, placebo-controlled, randomized clinical trial. J Clin Periodontol. 2012; 39(12):1149-58.

33. Miranda TS, Feres M, Perez-Chaparro PJ, et al. Metronidazole and amoxicillin as adjuncts to scaling and root planing for the treatment of type 2 diabetic subjects with periodontitis: 1-year outcomes of a randomized placebo-controlled clinical trial. $J$ Clin Periodontol. 2014; 41 (9): 890-9.

34. Tamashiro NS, Duarte PM, Miranda TS, et al. Amoxicillin plus Metronidazole therapy for patients with periodontitis and Type 2 diabetes: A 2-year randomized controlled trial. J Dent Res. 2016; 95(7):829-36.

35. Borges I, Faveri M, Figueiredo LC, et al. Different antibiotic protocols in the treatment of severe chronic periodontitis: A 1-year randomized trial. J Clin Periodontol. 2017 ;44(8):822-32.

36. Feres M, Figueiredo LC, Soares GM, Faveri M. Systemic antibiotics in the treatment of periodontitis. Periodontol. 2000. 2015; 67(1):131-86.

37. Sidana S, Mistry Y, Gandevivala A, Motwani N. Evaluation of the need for antibiotic prophylaxis during routine intra-alveolar dental extractions in healthy patients: a randomized double-blind controlled trial. J Evid Based Dent Pract. 2017; 17(3):184-9.

38. Lodi G, Figini L, Sardella A, Carrassi A, Del Fabbro M, Furness S. Antibiotics to prevent complications following tooth extractions. Cochrane Database Syst Rev. 2012; 11:CD003811.

39. Ren YF, Malmstrom HS. Effectiveness of antibiotic prophylaxis in third molar surgery: a meta-analysis of randomized controlled clinical trials. J Oral Maxillofac Surg. 2007; 65(10):1909-21.

40. Lang MS, Gonzalez ML, Dodson TB. Do antibiotics decrease the risk of inflammatory complications after third molar removal in community practices? J Oral Maxillofac Surg. 2017; 75(2):249-55.

41. Moloney J1, Stassen LF. Pericoronitis: treatment and a clinical dilemma. J Ir Dent Assoc. 2009; 55(4):190-2.

42. University of Toronto Faculty of Dentistry. Soft Tissue Biopsy. Available: https://patients.dentistry.utoronto.ca/node/435 [Accessed 06 June 2018].

\section{Do the CPD questionnaire on page 536}

The Continuous Professional Development (CPD) section provides for twenty general questions and five ethics questions. The section provides members with a valuable source of CPD points whilst also achieving the objective of CPD, to assure continuing education. The importance of continuing professional development should not be underestimated, it is a career-long obligation for practicing professionals.

\section{Online CPD in 6 Easy Steps}

Go to the SADA website www.sada.co.za.

2 Log into the 'member only' section with your unique SADA username and password.

3 Select the CPD navigation tab.

4 Select the questionnaire that you wish to complete.

5 Enter your multiple choice answers. Please note that you have two attempts to obtain at least $70 \%$.

$6 \quad$ View and print your CPD certificate. 